\title{
METÁFORAS NOVAS PARA REENCANTAR A EDUCAÇÃO EPISTEMOLOGIA E DIDÁTICA
}

\author{
BUFFON, M. C. M"1; CAVAШET, V. J.1
}

${ }^{1}$ Setor de Ciências Agrárias, Departamento de Fitotecnia e Fitossanitarismo, Curso de Pós-Graduação em Produção Vegetal, Disciplina Profissionalidade e Novos Paradigmas. UFPR

\section{RESENHA}

O autor inic ia sua obra, analisando os vários a spectos importantes rela cionados com a qualidade cognitiva e social da educação. Ele afima que o processo educacional, a melhoria pedagógic a e o compromisso social têm que caminhar juntos, e que um bom ensino da parte dos docentesnão é sinônimo automático de boa aprendizagem porparte dos alunos, ou seja, que há uma pressuposição equivocada de que uma boa pedagogia se resume num bom ensino. De acordo com o autor é imprescindível melhorar qua litativamente o ensino nassuasformas didáticas e na renovação e atua lização constante dos conteúdos. Ele define que educar não é apenas ensinar, mas criar situações de aprendizagem nas quais todos os aprendentes possam despertar, mediante sua própria experiência do conhec imento.

Este explic a que a escola não deve ser concebida como simples agência repassadora de conhec imentos prontos, mas como contexto e clima organizacional propíc io à inic iação em vivências personalizadas do aprender a aprender. A flexibilidade é um aspecto cada vez mais imprescindível de um conhecimento personalizado e de uma ética social democrática.

O conhecimento virou tema obrigatónio. Fala-se muito em socieda de do conhec imento e agora também em sociedade a prendente. É importante saber decodificarcriticamente e enc ararpositivamente o desafio pedagógic o expressado numa séne de novas linguagens.

Toda educação implica em doses fortes de instrução, entendimento e manejo de regras, e reconhec imento de saberes já acumula dos pela humanidade. Embora importante essa instrução não é o aspecto fundamental da educação, já que este reside na s vivências personalizadas de aprendizagem que obedecem à coincidência básica entre processos vita is e proc essos cognitivos.

No mundo atual, o aspecto instrucional da educação já não consegue darconta da profusão de conhecimentos disponíveis e emergentes mesmo em áreas específicas. Por isso, esta não deveria preocupar-se tanto com a memorização dos saberes instrumentais, privilegiando a capacidade de acessa-los, decodifica-los e maneja-los. O aspecto instrucional deveria estarem função da emergência do a prender, ou seja, da morfogênese personalizada do conhecimento. Isso pode ser ilustrado, por exemplo, com a visão da memória como um processo dinâmico.

É preciso substituir a pedagogia das certezas e dos saberes pré-fixados por uma pedagogia da pergunta, do melhoramento das perguntas e do acessamento de informações. Em pedagogia da complexidade, que saiba trabalhar com conceitos transversáteis, abertos para a surpresa e o imprevisto.

O reencanta mento da educação requera união entre sensibilidade sociale eficiência pedagógica. Portanto, o compromisso étic o-político do/a educador/a deve manifestar-se primordialmente na excelência pedagógica e na colaboração para um clima esperançador no próprio contexto escolar. 
Na segunda parte do livro ele fala da pós-modemidade e a globalização do mercado.

O objetivo desta reflexão é buscara ponte entre pós-modemidade/pós-modemismo e didática. O pós-modemo é uma certa valonização da razão lúdica. Poralgo a teoria de jogosé parte substancial da engenharia de sistemas cognitivos complexos. O pós-modemo é também um convite a relaxar, a não se levartão a sério.

O pós-modemismo é, sem dúvida a denúncia dasfissuras da racionalidade modema, mas é também a tentativa de reintroduzir a lógica nebulosa nas prátic as culturais.

O marco referencial do debate pós-modemista, embora importante, é insuficiente para discutire encararosnovosdesa fiosda educação na situação pós-modema. O debate pós-modemista geralmente não consegue sair do meio-de-campo, confuso e embolado, da crise das ciências humanase sociais, onde o que mais se escuta são la múrias nostálgicas em relação a redenções falidas.

Em meio ao aciramento competitivo, planetariamente globalizado, a educação se confronta com o desafio de unirca pacitação competente com formação humana solidánia, já que hoje a escola incompetente se revela como estruturalmente reacionária por mais que veicule discursos progressistas. Juntar as duas tarefas - habilitação competente e formação solidária - fic ou sumamente difícil, porque a maioria das expectativas do meio circundante (mercado competitivo) se volta quase exclusivamente para a demanda da eficiência (capacidade competitiva).

Na terceira parte, ele disc ute as novas metáforas sobre o conhec imento e fala sobre o final de um ciclo nas estratégias educacionais.

O ciclo que temina concentrou-se, por década, no aumento quantitativo da oferta escolar. Escolas portodo lado, tendência à universalização do acesso à escola enquanto espaço disponível. Nisso houve bastante êxito. A ênfase prioritánia dessa fase (aumento quantitativo) sobrevive, como um eco interpelativo, no mote: educação para todos. Mas agora a ênfase se desloca do quantitativo para o qualitativo. Daí o exuberante discurso sobre a qualidade, inscrito no que se passou a chamarnova estratégia educacional.

Permanece, por um lado, a preocupação por atender, em temos quantitativos, a demanda reprimida ou nem se quer ativada. Diz-se, porem, que faltou, no ciclo a nterior, o vinculo dessa expansão escolarcom asexigências de modemização do processo produtivo, espec ialmente em doisaspectos: a quisição de um colchão básico de competênciasflexíveis e multi-adaptáveis e concentração no eixo c ient́fico técnico, que se dizestarcomandando a dinâmica dos ajustes requeridos para o crescimento econômico. Passa-se, por isso, a cobrara ponte entre a escola e uma capacitação básica e flexível diante de um mercado de trabalho cada vez mais exigente no que se refere à versatilidade adaptativa do trabalha dore ao acompanhamento atualiza do dos avanç os científico-técnicos. Daía ênfase conjunta em cidadania e capacidade competitiva, qualidade e produtividade; em suma, cidadania competitiva e criatividade produtiva. Não há como ignorarque, nessa proposta, há muitos aspec tos irrecusáveis, assim como os há carregado de ambigüidade.

$\mathrm{Na}$ quarta parte ele discorre sobre a qualidade vista desde o pedagógico, afimando que no futuro ninguém sobreviverá, em meio à competitividade crescente do mercado, sem uma educação fundamental que lhe entregue os instrumentos para a satisfação de suas necessidades básicas de aprendizagem no que se refere a competências mínimase flexíveis. No fundo, é a isso que se refere à questão da qualidade. Eé também para isso que convergem os interesses, ainda incipientes e ambíguos, que setores do empresariado começam a demonstrar numa verdadeira universalização da educação básica. 
Enqua nto já acontecem, inegavelmente, algumasmanobraspoderosas para instaurar uma verdadeira cruzada em favorda educação pela/para a qualidade, e até se chega a falarpomposamente em pedagogia da qualidade, muitos persistem em ignora ro fato, ou o têm como insignificante, ou ainda o consideram um banal modismo passageiro.

As lingua genssobre qualidade func ionam, hoje, como temitónio ocupado. Já não estão livres e disponíveis para dizer com elas o que talvez desejańamos. Muitos ainda não se deram conta do fato de que o disc urso sobre a qualidade se encontra, agora, aprisionado dentro de um campo de significação bem detemina do. E, pelo menos por algum tempo, não será fácil arranca-lo de lá e liberta-lo para outros sentidos.

A referência central para conferir se um tipo de educação está atingindo níveis aceitá veis de qualida de é obviamente o processo pedagógico em si mesmo. Eo ceme do processo pedagógico deve serloc alizado nasexperiências do prazer de estarconhecendo, nas experiências de aprendizagem que são vividas como algo que faz sentido para as pessoas envolvidas e é humanamente gostoso, embora possa implicar também árduos esforços. Não basta melhorar a qualidade do ensino, a questão de fundo é melhorar a qualidade das experiências de aprendizagem. Neste sentido, para refletir sobre a qualidade de um processo educativo, nossa atenção deveria voltar-se, antes de tudo, para o problema seguinte: como criarmelhores situações de aprend izagem, melhores contextos cognitivos, melhorecologia cognitiva e melhores interações geradoras da vibração bio-psico-energética do sentir-se como alguém que está aprendendo.

Na quinta e última parte, o autor, relaciona a questão da cidadania com a exclusão social. Ele diz que o maior desa fio étic o da atualida de e, neste sentido, o fato maior desse nosso tempo é, sem dúvida, a presença de uma estarrecedora lógica da exclusão do mundo de hoje. Grandes contingentes da população mundial passam ao rol de "massa sobrante" e faltam as dec isões polític as necessárias para uma efetiva dignific ação de suas vidas.

O fasc ínio e a manipulabilidade da linguagem sobre a cidada nia fazcom que ninguém dê mostras de querer desistirdela. Pormais que se trivia lize e banalize, continua inegavelmente importante, embora o processo de expropriação dessa linguagem pelos setores mais conservadorestenha avançado assustadoramente.

Cidadania não pode significar mera atribuição abstrata, ou apenas fomalmente juńdica, de um conjunto de direitos e deveres básicos, comuns a todos os integrantes de uma nação, mas deve significar o acesso real, em junidicamente exigível, ao exercício efetivo desses direitos e ao cumprimento desses deveres. Não há, pois, cidadania sem a exigibilidade daquelasmediaçõeshistónicasque lhe confira conteúdo no plano da satisfação das necessidades e dos desejos, comespondentes àquela noção de dignidade humana que seja estendível a todos num contexto histórico determinado.

A mediação histórica fundamental da cidadania básica é o acesso seguro aos meios para uma existência humana digna. Daí a comelação estreita entre cidadania e trabalho (no sentido de emprego justa mente remunerado) na visão até hoje comum dessa temática. Para o trabalhadore seus dependentes, a cidadania se alicerça no direito a o trabalho.

Salta à vista que a questão do emprego, de todos os modos, permanece como um dos elos básicos entre cidadania e lógica da exclusão. 


\section{CONCLUSÃO}

O livro é um conjunto de reflexões integra das e direciona das aos vánios aspec tos que possam interferir na qualidade do processo educacional. O autor demonstra que está havendo uma série de descobertas fascinantes acerca de como se dá a experiência do conhec imento na vida das pessoas. Este fundamenta a convic ção de que hoje estamos em condições de entender melhora relação indissolúvel entre proc essos vita is e processos de conhec imento, não apenas no sentido do ditado "vivendo e aprendendo", mas num sentido mais profundo que nos leva a compreender que a própria vida se constitui intrinsecamente mediante processos de aprendizagem.

Ao longo do livro ASSMANN mostra-se que a complexidade deve transformar-se num principio pedagógico pela simples razão de que, os docentes devem estaratentos às fomas complexas que assumem, na vida dos aprendentes, essa relação intrínseca entre os processos vitaise processos do conhec imento. Nesta perspectiva acredita-se em refomas cumiculares no ensino universitánio brasileiro, que efetivamente possam contribuir com a formação de profissionais.

REFERÊNC IA

ASSMANN, H. Metáforas novas para reencantar a Educação Epistemologia e Didática. 2a edição - Editora UNIMEP, 1998. 